\title{
REALISATION OF THE CATEGORY OF POLITENESS AS THE WAY OF REPRESENTING THE LINGUACULTURAL TYPE
}

\author{
Yuliya P. Bolotina \\ Herzen State Pedagogical University of Russia (Volkhov Branch), Volkhov, Russia
}

\begin{abstract}
The paper touches upon the issue of linguistic personality and describes the linguistic and cultural character of the butler in the novel written by K. Ishiguro. The paper points the fact that linguacultural type of the butler represents the national English character but does it in an exaggerated way. Linguacultural analysis of the language and speech units in the text has made it possible to characterize the communicative behavior of the protagonist and at the same time to explain the reasons of such behavior. The research results show that the category of politeness takes the leading role in describing the communicative behaviour of the main character. Forms of its representation in the given text include numerous speech clichs and various euphemisms. Moreover, certain syntactic structures such as indirect forms of questions and some parenthetical constructions express politeness in the given text. Restraint, evasiveness, remoteness as well as attempt to avoid imperative structures and imposing one's opinion are also typical of the protagonist's communicative behaviour. The conducted research makes it possible to confirm conclusions made by other scholars who state that category of politeness is a dominant trait of the national English character. We can also conclude that the abovementioned markers of politeness are common for the communicative behaviour of the English.

Key words: category of politeness, communicative behaviour, concept, linguacultural type, text, linguistic personality, speech etiquette.

Citation. Bolotina Yu.P. Realisation of the Category of Politeness as the Way of Representing the Linguacultural Type. Vestnik Volgogradskogo gosudarstvennogo universiteta. Seriya 2, Yazykoznanie [Science Journal of Volgograd State University. Linguistics], 2018, vol. 17, no. 3, pp. 158-165. (in Russian). DOI: https:// doi.org/10.15688/jvolsu2.2018.3.16
\end{abstract}

УДК 81:008:316.28

Дата поступления статьи: 07.05.2018

ББК 81.006 .3

Дата принятия статьи: 04.06.2018

\section{РЕАЛИЗАЦИЯ КАТЕГОРИИ ВЕЖЛИВОСТИ КАК СПОСОБ РЕПРЕЗЕНТАЦИИ ЛИНГВОКУЛЬТУРНОГО ТИПАЖА}

\author{
Юлия Петровна Болотина \\ Санкт-Петербургский государственный педагогический университет им. А.И. Герцена \\ (Волховский филиал), г. Волхов, Россия
}

\begin{abstract}
Аннотация. В статье описано коммуникативное поведение английского лингвокультурного типажа «дворецкий» в аспекте категории «вежливость». Исследование проведено на материале романа К. Исигуро «Остаток дня», в котором образ дворецкого является гипертрофированной репрезентацией английского $\underset{\sigma}{\circ}$ национального характера. В работе представлены результаты комплексного лингвокультурологического ㄱ. анализа единиц языка и речи, что позволило определить особенности и причины коммуникативного поведения главного героя произведения. На примере дворецкого Стивенса показано, что важнейшими чертами коммуникативного поведения людей этой профессии являются сдержанность, уклончивость, дистантность, неимпозитивность. Их воплощению способствует реализация принципа вежливости, который проявляется в использовании многочисленных формул речевого этикета (особенно частотны формулы конвенционального гозвинения), речевых клише, эвфемизмов. Установлено, что в тексте романа категория вежливости экспли(0) цируется на синтаксическом уровне посредством косвенной формы вопросов и вводных оборотов. Прове-
\end{abstract}


денное исследование позволяет дополнить существующие в науке представления о том, что категория вежливости - это одна из доминант английского национального характера, а вышеуказанные маркеры присущи коммуникативному поведению англичан в целом и используются с целью демонстрации уважения к личности собеседника, предотвращения конфликтных ситуаций, а также сохранения межличностного дистанцирования.

Ключевые слова: категория вежливости, коммуникативное поведение, концепт, лингвокультурный типаж, текст, языковая личность, речевой этикет.

Цитирование. Болотина Ю. П. Реализация категории вежливости как способ репрезентации лингвокультурного типажа // Вестник Волгоградского государственного университета. Серия 2, Языкознание. 2018. - T. 17, № 3. - C. 158-165. - DOI: https://doi.org/10.15688/jvolsu2.2018.3.16

\section{Введение}

С позиций лингвокультурологии текст (или совокупность текстов) является хранителем культуры, формой отражения субъективированной языковой картины мира, а также обобщенным носителем знания о мире. В тексте объективируются тезаурус-словарь и знание, присущее языковой личности, он предстает перед нами «как сложное устройство, хранящее многообразные коды, способное трансформировать получаемые сообщения и порождать новые, как информационный генератор, обладающий чертами интеллектуальной личности» [Лотман, 1992, с. 132].

Одним из элементов картины мира, peaлизованной в тексте, является лингвокультурный типаж, который В.И. Карасик предлагает включить в классификацию концептов. При этом под лингвокультурным типажом ученый понимает «узнаваемые образы представителей определенной культуры, совокупность которых и составляет культуру того или иного общества» [Карасик, 2007, с. 88]. Исследователь приводит в качестве примера наиболее яркие типажи: чудак в английской культуре человек с забавными странностями в поведении, обычно увлеченный каким-либо занятием и никому не причиняющий неудобств; юродивый в русской средневековой культуре нищий, придурковато-блаженный, истязающий себя и обладающий даром прорицания человек, и т. п. [Карасик, 2007, с. 89].

Общее определение лингвокультурного типажа (ЛТ) дает О.А. Дмитриева: «Языковая личность в ракурсе лингвокультурологии» [Дмитриева, 2007, с. 56]. При этом исследователь отмечает, что «коммуникативное поведение ЛТ регулируется ценностными приоритетами, стереотипами, архетипами»
[Дмитриева, 2007, с. 57], то есть связано с особенностями воспитания человека, его местом рождения и обучения, со средой, в которой он привычно общается, со всеми свойственными ему как представителю социальной группы чертами.

Речевая коммуникация представляет собой «стратегический процесс», основой которого является «оптимальный выбор языковых ресурсов» [Иссерс, 2008, с. 10]. Одной из разновидностей этого процесса следует признать речевой этикет, который определяется как система «языковых средств, материально выражающих в общении коммуникативную этику, воплощающих ее в языковой форме» [Стернин, 2003, с. 27]. В основе речевого этикета лежат следующие универсальные принципы общения: «сдержанность, вежливость, использование стандартных речевых формул в стандартных ситуациях общения, позитивное отношение к собеседнику» [Стернин, 1996, с. 13]. В качестве ведущего критерия этикетного речевого общения выступает принцип вежливости, который характеризует как вербальное, так и невербальное поведение человека.

Категория вежливости за последние десятилетия стала предметом дискуссий и получила множество интерпретаций в научной литературе. Например, в концепции П. Браун и С. Левинсона вежливость понимается как ряд мер по сохранению социального лица (facesaving) путем смягчения ликоугрожающих актов (Face Threatening Acts) [Brown, Levinson, 1978]. Р. Лакофф интерпретирует эту категорию как некий инструмент для сглаживания трения в межличностном взаимодействии [Lakoff, 1975]. Б. Хилл считает, что вежливость следует толковать как ограничения, которые накладываются на взаимодействие людей с целью поддержания необходимого уровня взаим- 
ного комфорта [Hill et al, 1986, p. 349]. По мнению М. Сифиану, категория непосредственно связана с культурными ценностями, так как это «набор социальных ценностей, предписывающий участникам учитывать интересы друг друга путем удовлетворения взаимных ожиданий» [Sifianou, 1992, p. 86]. Вежливость, согласно С.Ю. Тюриной, является «речеповеденческой категорией» и реализуется в речи определенным набором лексико-грамматических и просодических средств, основная цель использования которых состоит в достижении положительного коммуникативного эффекта [Тюрина, 2008, с. 46]. Таким образом, вежливость можно определить как средство поддержания гармоничных отношений с окружающими, которое основывается на соблюдении социальных норм и отражает принятые в обществе ценности. Более того, данная категория, с одной стороны, шире, чем речевой этикет, с другой - тесно связана с ним, так как реализуется в конкретных этикетных формулах.

Можно выделить не только универсальные принципы вежливости и формулы речевого этикета, но и те, которые в значительной степени обусловлены национальной культурой: «коммуникативное поведение людей является компонентом их национальной культуры и регулируется национальными нормами и традициями, в основе которых лежат глубокие исторические корни» [Ларина, 2003a, с. 48]. Цель нашего исследования - охарактеризовать коммуникативное поведение английского лингвокультурного типажа «дворецкий» в аспекте категории «вежливость».

\section{Материал исследования}

Выбор лингвокультурного типажа «дворецкий» в качестве объекта исследования обусловлен тем, что дворецкий - один из самых узнаваемых характеров английской литературы. Реализацией его в современной англоязычной литературе можно рассматривать дворецкого Стивенса - главного героя романа К. Исигуро «Остаток дня». Отметим, что, создавая этот образ, автор опирается на национально-культурные традиции: литературными прототипами Стивенса выступают Лейн (Lane) из произведения O. Уайльда «Как важ- но быть серьезным» (The Importance of Being Earnest by O. Wilde), знаменитый Дживз из серии рассказов П.Г. Вудхауса (Jeeves and Wooster by P.G. Wodehouse) и др.

\section{Методы исследования}

Коммуникативное поведение главного героя романа «Остаток дня» исследуется с применением комплексного подхода к анализу лексических и синтаксических единиц, реализующих содержание категории вежливости в тексте. Использованы описательный и интерпретационный методы анализа языковых и речевых средств объективации вежливости, при этом учитывалась степень повторов и частотность употребления тех или иных единиц в тексте произведения.

\section{Результаты исследования}

Свод приличных манер, вежливость, воспроизведенные в романе «Остаток дня», являются такой же типичной чертой английской действительности, как пейзаж или обстановка в доме. Например, П. Лэнгфорд, завершая анализ английской сдержанности, писал, что претензия англичан на учтивость и аристократические замашки, утратившая для других наций статус образца общественного развития, стала едва ли чем-то большим, чем маской неисправимой национальной необщительности [Langford, 2000, p. 265]. По мнению исследователей, дворецкий в романе Исигуро «предстает своего рода квинтэссенцией английского характера» [Джумайло, 2014, с. 201]. Так, для главного героя и рассказчика вежливость и учтивость становятся маской, позволяющей скрывать, мысли и истинные чувства. Стивенс настолько привык облекать все свои мысли в формализованные конструкции, что вкупе со сдержанностью они становятся своеобразным барьером, «розовыми очками», позволяющими даже самому себе не признаваться в том, что на самом деле происходит у него в душе: «В ремарках Стивенса нет ни слова об эмоциях: улыбка, кивок - традиционные формы вежливости - замещают целый спектр чувств» [Джумайло, 2014, с. 207]. От начала и до самого финала романа фразы I smiled; I laughed; I gave a small laugh - 
единственные формы выражения эмоций дворецкого. Герой изо всех сил пытается контролировать свои эмоции, заменяя их улыбкой, даже зная о том, что его отец умирает:

(1) I turned to find the young Mr. Cardinal beaming happily at me. I smiled also and said: 'Fish, sir'?

... I say, Stevens, are you all right?

I smiled again. 'Quite all right, thank you, sir' (p. 47).

Только прямолинейность и несдержанность мисс Кентон может вывести его из равновесия:

(2) To my astonishment, Miss Kenton responded to this in a sudden burst: 'Mr. Stevens, I have had a very busy week. I am very tired. In fact, I have been wishing for my bed for the last three or four hours. I am very, very tired, Mr. Stevens, can you not appreciate that?' (p. 74).

Однако даже эти редкие для главного героя эмоции не находят внешнего проявления, дворецкому удается сохранять самообладание, оставаться подчеркнуто вежливым и уклоняться от манифестации своих подлинных чувств во всех конфликтах с мисс Кентон, даже когда она возмущена увольнением двух служанок-евреек:

(3) I am telling you, Mr. Stevens, if you dismiss my girls tomorrow, it will be wrong, a sin as any sin ever was one and I will not continue to work in such a house.

Miss Kenton, let me suggest to you that you are hardly well placed to be passing judgements of such a high and mighty nature (p. 63).

Необходимо отметить, что мисс Кентон является антиподом главного героя, она, как мы видим в приведенном выше отрывке, в отличие от Стивенса не склонна скрывать истинные чувства, физическое состояние. Для нее преувеличенная вежливость - форма выражения иронии или даже сарказма:

(4) I am most indebted to you for your advice, Mr. Stevens. So do please tell me, just what marvelous things might I learn from observing your father? (p. 24).

Необходимо отметить, что в теории Дж. Калпепера такое поведение трактуется как «мнимая вежливость» (mock politeness), которая используется с целью нарушения гармоничных отношений в обществе. В таком случае вежливость реализуется только на поверхностном уровне (surface realizations) [Culpeper, Bousfield, Wichmann, 2003, p. 1555]. Автор романа намеренно вкладывает в уста мисс Кентон несколько различных средств выражения вежливости (обычно речь героини не столь насыщена такими элементами), стремясь подчеркнуть неискренность. Контраст подчеркивает и стилистически окрашенная речь героини (усилитель most, эмфатическия конструкция do tell, эпитет marvelous), в то время как реплики Стивенса содержат нейтральные лексические единицы.

Речь дворецкого изобилует устойчивыми формулами речевого этикета, характерными для британцев: обращения (sir, madam), клише для выражения извинения (I beg your pardon, I'm sorry, excuse me), благодарности (thank you), удовольствия (pleased to hear that), согласия (indeed, of course), опасения (I'm afraid, I fear). Приведем пример одного из диалогов Стивенса с гостьей дома, насыщенного такими клише:

(5) 'You will compliment the cook for me, Stevens,' she said.

'Of course, madam. Thank you, madam.'

'And you and your team did well also.'

'Thank you most kindly, madam.'

'At one point during dinner, Stevens, I would have sworn you were at least three people,' she said and laughed.

I laughed quickly and said: 'I'm delighted to be of service, madam' (p. 48).

Даже наедине с собой Стивенс облекает мысли в привычные ему формулы:

(6) I am glad to be able to recall numerous occasions when the silver at Darlington Hall had a pleasing impact upon observers (p. 57).

Речевые клише, для которых характерна значительная степень десемантизации, становятся для него спасительной соломинкой и в разговоре с умирающим отцом. Отец, понимая, что необходимо подвести некий жизненный итог, пытается понять, был ли он хорошим для своего сына. Стивенс вместо искреннего ответа прибегает к универсальной фразе, уместной, по его мнению, в разговоре с больным: 
(7) I hope Father is feeling better now (p. 43).

Пытаясь скрыть свое волнение, трижды повторяет те же ничего не значащие фразы:

(8) I'm very glad Father is feeling better. I'm so glad you're feeling better now. I'm so glad you're feeling better now (p. 43).

Типичное проявление вежливости в английской культуре - применение таких этикетных форм межличностного общения, как конвенциональные извинения, которые произносятся в связи с незначительными нарушениями этикета [Ратмайр, 2003, с. 159]. Это коммуникативное поведение в британском обществе, по мнению В.А. Литвиновой, обусловлено конвенцией приватности личного пространства и предупредительного отношения к собеседнику [Литвинова, 2017, с. 163]. Главный герой романа К. Исигуро придает большое значение соблюдению конвенций, и любое самое незначительное отступление от нормы заставляет его прибегать к различным формулам конвенциональных извинений:

(9) I'm very sorry, sir.

My goodness, Stevens. You gave me a shock. I thought things were hotting up a bit there.

I'm very sorry, sir. But as it happens, I have something to convey to you.' ..... 'Excuse me, sir. I must attend to him straight away.

Of course, Stevens. Well, kind of you to have come out to talk to me.

Please excuse me, sir (p. 40).

Автор романа использует клишированные формы конвенциональных извинений, воспроизводя размышления главного героя, демонстрируя таким образом, что даже наедине с самим собой Стивенс стремится соблюдать все принятые в обществе нормы и правила поведения:

(10) In any case, I am sorry to report that what the local people had themselves offered last night as a witticism of sorts - the prediction that I would not have a good night owing to disturbances from below proved only too true (p. 56).

Следующей особенностью вежливого коммуникативного поведения является эвфемизация речи, которая свойственна всем культурам, в том числе и британской. Стивенс в совершенстве владеет смягчающими приемами ведения разговора и использует различные эвфемистические номинации:

(11) You will excuse me, but there are one or two other small things I might mention... It is not like you to have overlooked such obvious things, Miss Kenton (p. 76).

Этой цели служит и употребление модальных глаголов:

(12) That would be most awkward, sir (p. 38).

Английское коммуникативное поведение характеризуется также неимпозитивностью и предполагает отсутствие или сведение к минимуму прямого коммуникативного воздействия на адресата [Ларина, 2003б, с. 140]. Одним из способов проявления неимпозитивности можно считать уклончивость неотъемлемую черту речи дворецкого:

(13) Oh, Stevens, perhaps you're the one to tell me. This arch here looks seventeenth century, but isn't it the case that it was built quite recently? Perhaps during Lord Darlington's time?'

It is possible, madam.

It's very beautiful. But it is probably a kind of mock period piece done only a few years ago. Isn't that right?

I'm not sure, madam, but that is certainly possible (p. 54).

Характерное для англичан избегание императивности также выражается в использовании косвенной формы выражения просьбы в виде вопросов с модальными глаголами:

(14) Indeed. In any case, may I be assured Father will study that sheet? (p. 29).

Стремление не навязывать своего мнения собеседнику, характерное для коммуникативного поведения британцев, тоже нашло отражение в речи Стивенса: он постоянно использует такие вводные обороты и наречия, как I believe, it is my impression, perhaps, probably и т. п.:

(15) I feel I should perhaps return a moment to the question of his lordship's attitude to Jewish persons, since this whole issue of anti-Semitism, I realize, has become a rather sensitive one these days (p. 61). 
Таким образом, коммуникативное поведение главного героя романа К. Исигуро «Остаток дня» характеризуется использованием многочисленных этикетных клише, в том числе и формул конвенционального извинения. Кроме того, в качестве основных характеристик речи дворецкого следует отметить эвфемизацию и отсутствие импозитивности.

\section{Заключение}

Различные маркеры вежливости являются одним из средств создания лингвокультурного типажа дворецкого, персонажа, для которого внешняя оболочка (приличные манеры, набор уместных клише, умение уклониться от прямого ответа и т. п.) важнее, чем содержание и подлинные эмоции. Такие культурно-обусловленные признаки вежливости, представленные в романе К. Исигуро в гипертрофированной форме, репрезентируют английский менталитет и позволяют подтвердить выводы исследователей о сдержанности как одной из доминант английского национального характера.

Исигуро намеренно списывает своего дворецкого с героев произведений других английских авторов. Однако его герой становится трагической фигурой - внешняя форма, стремление как можно более деликатно выражать свои мысли, заслоняет главное - в финале романа он понимает, что робкие надежды на возвращение мисс Кентон в Дарлингтон-холл не оправдаются, любовь была упущена, а его служение лорду Дарлингтону тоже оказалось лишенным глубокого смысла.

Стивенс отгородился от любого проявления искренности завесой этикетных формул. Примечательно в этом отношении высказывание В.В. Кобзевой, которая, развивая идеи Э. Сепира, объясняет такое поведение людей тем, что «правила и нормы этикета носят формализованный характер и не вынуждают человека выбирать между добром и злом, правдой и ложью, как этого требуют моральные заповеди. Предписания этикета в основном диктуют требования общечеловеческой культуры, вежливости, обходительности, учтивости, приветливости, но при этом они регламен- тируют иерархию возрастных, статусных, половых различий людей. В правилах этикета заранее предусматриваются ситуации и даются готовые модели конкретных действий» [Кобзева, 2003, с. 116]. Эта тактика в современной Британии используется не только дворецкими или другим обслуживающим персоналом. Дворецкий становится для Исигуро воплощением национального менталитета британцев. В одном из интервью он пишет: «I chose the figure deliberately because that's what I think I am, and I think most of us are: We're just butlers» (цит. по: [Lewis, 2000, p. 77]) - Я выбрал героя-дворецкого неслучайно, так как думаю, что сам, по сути, дворецкий. Думаю, большинство из нас не более чем дворецкие (перевод наш. - Ю. Б.), то есть тоже носят маски вежливости, камуфлируя равнодушие и разобщенность.

\section{СПИСОК ЛИТЕРАТУРЫ}

Джумайло О. А., 2014. Английский исповедальнофилософский роман 1980-2000 гг. : дис. ... д-ра филол. наук. Ростов-на-Дону. 318 с.

Дмитриева О. А., 2007. Лингвокультурные типажи России и Франции XIX века. Волгоград : Изд-во ВГПУ «Перемена». 307 с.

Иссерс О. С., 2008. Коммуникативные стратегии и тактики русской речи. М. : Изд-во ЛКИ. 288 с.

Карасик В. И., 2007. Лингвокультурный типаж // Язык. Текст. Дискурс : Научный альманах. Ставропольского отделения РАЛК / под ред. проф. Г. Н. Манаенко. Вып. 5. Ставрополь ; Пятигорск : Изд-во ПГЛУ. С. 86-89.

Кобзева В. В., 2003. Этикет в вопросах и ответах. М. : Гранд. $283 \mathrm{c}$.

Ларина Т. В., 2003а. «Вежливость» как компонент коммуникативного сознания // Коммуникативное поведение. Вып. 17. Вежливость как коммуникативная категория / науч. ред. И. А. Стернин. Воронеж : Изд-во «Истоки». C. 48-57.

Ларина Т. В., 2003б. Категория вежливости в английской и русской коммуникативных культуpax. М. : Изд-во РУДН. 315 с.

Литвинова В. А., 2017. Лингвокультурная специфика речевого акта «этикетное извинение» в британской коммуникативной традиции // Вестник Волгоградского государственного университета. Серия 2 , Языкознание. Т. 16, № 2. С. 160-167. DOI: https://doi. org/10.15688/jvolsu2.2017.2.17 
Лотман Ю. М., 1992. Семиотика культуры и понятие текста // Избранные статьи: в 3 т. Т. 1. Таллинн : Изд-во «Александра». С. 129-132.

Ратмайр Р., 2003. Прагматика извинения: Сравнительное исследование на материале русского языка и русской культуры. М. : Языки славянской культуры. 272 с.

Стернин И. А., 1996. Русский речевой этикет. Воронеж : Изд-во ВОИПКРО. 73 с.

Стернин И. А., 2003. Проблемы описания вежливости как коммуникативной категории // Коммуникативное поведение. Вып. 17. Вежливость как коммуникативная категория. Воронеж : Изд-во «Истоки». С. 22-47.

Тюрина С. Ю., 2008. Дискурсивные маркеры вежливости в деловом общении // Вестник Ивановского государственного энергетического университета. Вып. 1. С. 46-49.

Brown P., Levinson S., 1978. Universals in language usage: Politeness phenomena // Questions of politeness: Strategies in social interaction. Cambridge : Cambridge University Press. P. 56-310.

Culpeper J., Bousfield D., Wichmann A., 2003. Impoliteness revisited: with special reference to dynamic and prosodic aspects // Journal of Pragmatics. № 35. P. 1545-1579.

Hill B. et al, 1986. Hill B., Ide S., Ikuta S., Kawasaki A., Ogino T. Universals of linguistic politeness: quantitative evidence from Japanese and American English // Journal of Pragmatics. Vol.10. №3. P. 347-371.

Lakoff R., 1975. Language and Women's Place. New York : Harper \& Row. 328 p.

Langford P., 2000. Englishness identified. Oxford : Oxford University Press. 408 p.

Lewis B., 2000. Kazuo Ishiguro. Manchester ; New York: Manchester University Press. 191 p.

Sifianou M., 1992. Politeness Phenomena in England and Greece. Oxford: Clarendon. 268 p.

\section{ИСТОЧНИКИ}

Isiguro K., 1989. The Remains of the Day. London : Faber and Faber Limited. 101 p.

\section{REFERENCES}

Dzhumailo O.A., 2014. English confessionphilosophical novel of 1980-2000s: Dr. philol. sci. diss. Rostov-on-Don. 318 p.

Dmitrieva O.A., 2007. Linguacultural types of Russia and France of the 19th century. Volgograd, Peremena Publ. 307 p.
Issers O.S., 2008. Communicative strategies and tactics of the Russian speech. Moscow, LKI Publ. 288 p.

Karasik V.I., 2007. Linguacultural type. Manaenko G.N., ed. Yazyk. Tekst. Diskurs. Nauchnyy almanakh Stavropolskogo otdeleniya RALK. Stavropol; Pyatigorsk, Izd-vo PGLU, iss. 5, pp. 86-89.

Kobzeva V.V., 2003. Etiquette in questions and answers. Moscow, Grand Publ. 283 p.

Larina T.V., 2003a. Politeness as a component of communicative consciousness. Sternin I.A., ed. Kommunikativnoe povedenie. Vezhlivost kak kommunikativnaya kategoriya. Voronezh, Istoki Publ., iss. 17, pp. 48-57.

Larina T.V., 2003b. The category of politeness in English and Russian communicative cultures. Moscow, RUDN Publ. 315 p.

Litvinova V.A., 2017. Linguacultural specifity of the speech act "etiquette apology" in the British communicative tradition. Vestnik Volgogradskogo gosudarstvennogo universiteta. Seriya 2, Yazykoznanie [Science Journal of Volgograd State University. Linguistics], vol. 16, no. 2, pp. 160-167. DOI: https://doi.org/10.15688/ jvolsu2.2017.2.17.

Lotman Yu.M., 1992. Semiotics of culture and concept of text. Izbranniye statyi. T.1. Tallin, Aleksandra Publ., pp. 129-132.

Ratmair R., 2003. Apology pragmatics: Comparative apology based on the Russian language and Russian culture. Moscow, Yazyki slavyanskoy kultury Publ. 272 p.

Sternin I.A., 1996. Russian speech etiquette. Voronezh, VOILKRO Publ. 73 p.

Sternin I.A., 2003. The problems of describing politeness as a communicative category. Sternin I.A., ed. Kommunikativnoe povedenie. Vezhlivost kak kommunikativnaya kategoriya. Voronezh, Istoki Publ., pp. 22-47.

Tyurina S.Yu., 2008. Discursive markers of courtesy in business communication. Vestnik Ivanovskogo gosudarstvennogo energeticheskogo universiteta [Vestnik of Ivanovo State Power Engineering University], iss. 1, pp. 46-49.

Brown P., Levinson S., 1978. Universals in language usage: Politeness phenomena. Questions of politeness: Strategies in social interaction. Cambridge, Cambridge University Press, pp. 56-310.

Culpeper J., Bousfield D., Wichmann A., 2003. Impoliteness revisited: with special reference to dynamic and prosodic aspects. Journal of Pragmatics, no. 35, pp. 1545-1579.

Hill B., Ide S., Ikuta S., Kawasaki A., Ogino T., 1986. Universals of linguistic politeness: quantitative evidence from Japanese and 
Ю.П. Болотина. Реализация категории вежливости как способ репрезентации лингвокультурного типажа

American English. Journal of Pragmatics, vol. 10, no. 3, pp. 347-371.

Lakoff R., 1975. Language and Women's Place. New York, Harper \& Row. 328 p.

Langford P., 2000. Englishness identified. Oxford, Oxford University Press. 408 p.

Lewis B., 2000. Kazuo Ishiguro. Manchester; New York, Manchester University Press. 191 p.
Sifianou M., 1992. Politeness Phenomena in England and Greece. Oxford, Clarendon. 268 p.

\section{SOURCES}

Isiguro K., 1989. The Remains of the Day. London, Faber and Faber Limited. $101 \mathrm{p}$.

\section{Information about the Author}

Yuliya P. Bolotina, Candidate of Sciences (Philology), Associate Professor of Department of Humanities Education and Pedagogical Technologies, Herzen State Pedagogical University of Russia (Volkhov Branch), Oktyabrskaya Emb., 1A, 187401 Vokhov, Russia, bolotinayulia@yandex.ru, https:// orcid.org/0000-0001-8106-0184

\section{Информация об авторе}

Юлия Петровна Болотина, кандидат филологических наук, доцент кафедры гуманитарного образования и педагогических технологий, Российский государственный педагогический университет им. А.И. Герцена (Волховский филиал), наб. Октябрьская, 1А, 187401 г. Волхов, Россия, bolotinayulia@yandex.ru, https://orcid.org/0000-0001-8106-0184 